\title{
Perceived Self-Efficacy, Outcome Expectations and Self-Care Behavior of Hypertensive Patients Received a Treatment at Hinlub Subdistrict Health Promotion Hospital, Muak Lek District, Saraburi Province, Thailand
}

\author{
Pornpan Saminpanya ${ }^{1}$, Ampaiwan Toomsan², Supatcharee Makornkan ${ }^{3}$ \\ Asia-Pacific International University
}

\begin{abstract}
This research examined and compared the levels of perceived self-efficacy, outcome expectations, and self-care behavior of hypertensive patients who received treatment at the studied area. Purposive sampling of 76 patients (21 males and 55 females) who had blood pressure controlling under 160/100 mmHg., answered the questionnaires (Alpha-reliability Coefficient as 0.96) from August to November 2017. The statistics used included frequency, percentage, mean, standard deviation, one sample t-test, one-way ANOVA with comparison test by Scheffe's method, and Stepwise-multiple regression. The results were as follows: (a) a whole of the three aspects is at high level when comparing with the established criteria (60\%) at the .05 level of significance with an average mean of 3.56; (b) comparison between genders is not significant, only income makes the three issues significantly different at the .05 level of significance. The best predictor of self-efficacy perception is appropriate time selection for exercises, which could predict the self-care behavior at 48.70 percent and at the .05 level of significance.
\end{abstract}

Keywords: perceived self-efficacy, outcome expectations, self-care behavior, hypertensive patients 